\title{
TRANSFORMAÇÕES DO/NO PAÍS DO FUTURO: sentidos sobre educação, trabalho e desenvolvimento social
}

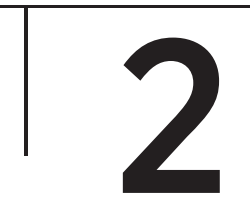

\section{TRANSFORMATIONS OF/IN THE COUNTRY \\ OF THE FUTURE: sense about education, work and social development}

\begin{abstract}
SILVA, Cristiane Lilian Ferreira
Mestranda do Programa de Pós-Graduação em Estudos Linguísticos da Universidade Estadual

Paulista - UNESP/IBILCE.

E-mail: crika_praxedes@hotmail.com

GALLI, Fernanda Correa Silveira

Doutora em Estudos Linguísticos (UNESP-SJRP/PNPD-CAPES)

Pós-doutora em Ciência da Informação e Comunicação (USP-FFCLRP/FAPESP)

Docente dos Programas de Pós-graduação em Estudos Linguísticos (PPGEL/UNESP-SJRP) e do

Programa de Linguística da Universidade Federal de Pernambuco (PROLING/UFPB)

E-mail: fcsgalli@hotmail.com
\end{abstract}

\section{RESUMO:}

Com base na perspectiva da Análise do Discurso francesa, pretendemos, neste artigo, refletir a respeito dos efeitos de sentido de materialidades - a saber, um recorte do e-book intitulado Estratégia brasileira para a transformação digital e o enunciado Brasil, país do futuro em diferentes espaços midiáticos - que tratam de transformações do/no país do futuro. De modo específico, buscamos, por meio da noção de memória discursiva, desenvolvida por Pêcheux (2010), analisar a emergência das concepções de educação, de trabalho e de desenvolvimento social no Brasil.

Palavras-chave: análise de discurso; país do futuro; memória discursiva; efeitos de sentido.

\section{ABSTRACT:}

Based on the perspective of Peuchex's Discourse Analysis, in this article we aim to reflect on the effects of meaning of materialities - namely, a crossover of the e-book entitled Estratégia brasileira para a transformação digital (The Brazilian Digital Transformation Strategy) 
and the statement Brasil, país do futuro (Brazil, country of the future) in different media spaces - that deal with transformations of/in the country of the future. In a specific way, we seek to analyze the emergence of conceptions of education, work and social development in Brazil through the notion of discursive memory, developed by Pêcheux (2010).

Keywords: discourse analysis; country of the future; discursive memory; sense effects.

\section{CONSIDERAÇÕES INICIAIS}

Recentemente, assuntos ligados diretamente à política e aos governantes têm circulado de forma intensa no cotidiano de brasileiros, fazendo com que a esfera que conjuga a comunicação entre Estado e população seja discutida e repensada. O principal terreno onde esse debate acontece é o espaço digital da internet, por meio das redes sociais, jornais on-line, blogs etc. Através desses canais, muitos questionamentos vêm à tona, propiciando a emergência de ideias, de discursos, de contradiscursos, e, ainda, de memórias que retornam e se ressignificam. Pela veiculação constante de notícias (nem sempre verdadeiras, como é caso das Fake News) ${ }^{1}$, memes ${ }^{2}$ e charges que abordam a relação Estado/ povo pode-se notar o movimento dos discursos que emergem e que são silenciados, no jogo de resistência e das relações de força e de poder. Assim, é possível perceber o quanto a noção de memória, postulada por Pêcheux (2010), torna-se importante para que possamos compreender os efeitos de sentido e os modos como os discursos atravessam os sujeitos.

Nessa perspectiva, interessa-nos refletir sobre os enunciados que abordam temas relacionados à educação, trabalho e desenvolvimento social no Brasil; dito de outro modo, buscamos investigar de que forma tais temas têm circulado no espaço digital da internet e como se dão os movimentos de emergência e de apagamento de dizeres que envolvem a questão do desenvolvimento econômico e social do país. Parte do material analisado integra o intitulado Estratégia brasileira para

\footnotetext{
1 Segundo a startup PSafe, 4,4 milhões notícias falsas foram compartilhadas no período das pré-eleições presidenciais de 2018. Disponível em: < https://canaltech.com.br/internet/brasil-tem-mais-de-4-milhoes-de-casosde-fake-news-no-segundo-trimestre-120592/>. Acesso em: 01 mai 2019.

2 Imagem, vídeo, frase, expressão, parte de um texto etc., copiada e compartilhada rapidamente e através da Internet, por um grande número de pessoas, geralmente com um teor satírico, humorístico ou para zoar uma situação ou pessoa. Elemento cultural, geralmente comportamental, que é passado de um indivíduo para outro por meio da imitação ou por outras razões não genéticas. Etimologia (origem da palavra meme). Do grego mimema, imitação; pelo inglês meme. Disponível em: <https://www.dicio.com.br/meme/>. Acesso em: 01 mai. 2019.
} 
a transformação digital, e-book ${ }^{3}$ desenvolvido pela equipe do Ministério da Ciência, Tecnologia, Inovação e Comunicação (MCTIC), o qual contempla a política nacional de inclusão digital e tem como enfoque principal o desenvolvimento de "serviços públicos relevantes para o desenvolvimento do país". ${ }^{4}$ Uma das diretrizes desse Ministério é incluir digitalmente a sociedade brasileira como um todo, a partir de uma rede de secretarias e políticas públicas (nível estadual e municipal) interligadas ao MCTIC para desenvolver planos e projetos que implementem a proposta da inclusão digital. A escolha desse material tem relação com o fato de que, em nossa pesquisa de mestrado, ${ }^{5}$ temos como objetivo estudar os discursos sobre a inclusão digital, ou seja, os enunciados que fazem circular - por presença ou por ausência - as possibilidades de alçamento econômico da camada adulta e de sua inserção social por meio do letramento digital.

Integra, ainda, o conjunto do material que aqui analisamos: o enunciado Brasil, país do futuro, o qual tem circulado nos diferentes espaços midiáticos. Inicialmente, o referido enunciado apareceu como título de um livro - Brasil, país do futuro (ZWEIG, 1941) - e, posteriormente, foi reformulado e lançado como slogan político durante a ditadura militar. A justificativa para o agrupamento desse enunciado em circulação, em nosso percurso de análise, com o recorte já citado, se deve ao fato de que são materialidades cujos efeitos de sentido se atravessam, se deslocam e se complementam. A busca pelo enunciado no espaço digital da internet foi aleatória, de modo que a rede nos direcionou à uma infinidade de sites e blogs que tratam de atualidades e política, e nos apontou a "origem" do enunciado do qual estamos tratando. Nessa busca, pudemos perceber que algumas formulações propagadas no formato de charge e título de notícia (muitas delas atuais no que tange ao momento político pelo qual o Brasil passa) retomam o enunciado Brasil, país do futuro e, ao mesmo tempo, seja pelo dito ou pelo não-dito. Procuramos, portanto, analisar se e como as concepções de educação, de trabalho e de desenvolvimento social no Brasil emergem no material abordado, o qual, de nosso ponto de vista, trata, de algum modo, de transformações do/no país do futuro. Antes, apresentamos os conceitos de discurso e de memória discursiva.

\footnotetext{
3 Livro virtual, escrito em seu formato original, mas disponibilizado e difundido através da Internet.

4 Disponível em: <http://www.mctic.gov.br>. Acesso em: 05 mai. 2019.

5 Em andamento no Programa de Pós-graduação em Estudos Linguísticos da UNESP - campus de São José do Rio Preto.
} 


\section{FUNDAMENTAÇÃO TEÓRICA}

Michel Pêcheux é considerado um dos expoentes da Análise do Discurso (AD) francesa, pois desenvolveu diversos conceitos, viabilizando e sedimentando a teoria discursiva, a qual tem como centro a articulação entre o discurso, a língua, o sujeito e a história. Maldidier (2003) esclarece que a conjuntura teórica na qual se inicia o desenvolvimento da $\mathrm{AD}$ se dá em uma época de proeminência do estruturalismo, concomitante ao marxismo althusseriano, propiciando a reflexão sobre a instância ideológica, e abrindo portas em direção à psicanálise. Neste contexto, surge um campo de pesquisa em que um novo objeto emerge - o discurso, "lugar teórico em que se intrincam literalmente todas as suas (de Pêcheux), grandes questões sobre a língua, a história, o sujeito" (MALDIDIER, 2003, p. 15).

Maldidier (2003, p.21) destaca, com base nas reflexões epistemológicas desenvolvidas por Pêcheux, que a teoria do discurso proposta por esse teórico como "teoria geral da produção dos efeitos de sentidos", não vem substituir nem uma teoria da ideologia nem uma teoria geral da produção dos efeitos de sentidos e, nem tampouco, uma teoria do inconsciente, "mas poderá intervir no campo dessas teorias". Desse modo, o discurso deve ser tomado como um conceito que não é nem o discurso empírico sustentado por um sujeito nem pelo texto, e sim um conceito que extrapola qualquer concepção comunicacional da linguagem (MALDIDIER, 2003). Baseando-se na língua (concebida como sistema no sentido saussuriano), o discurso reformula a fala. Segundo a fórmula althusseriana, o discurso supõe "uma mudança de terreno", ou seja, a intervenção de conceitos exteriores à linguística, definindo, assim, o novo objeto - baseado em uma dupla fundamentação, quais sejam: a língua e a história, ou seja, trata-se de uma construção que "não invoca de forma alguma a 'superação' da dicotomia língua/fala. Saussure é, para Pêcheux, "o ponto de origem da ciência linguística" (MALDIDIER, 2003, p. 22). Nessa perspectiva, podemos dizer que o discurso é uma unidade heterogênea, já que é atravessado por três elementos - a psicanálise, a linguística e o materialismo histórico - que não funcionam de maneira sobreposta ou em uma relação de hierarquia entre si, pelo fato de que suas interferências não podem serem demarcadas de maneira estanque, ou seja, trata-se de um objeto constituído pela língua, pela história e pelo sujeito.

Cada um desses elementos contribui para a base teóricometodológica da $\mathrm{AD}$ francesa e tem uma relação não marcada unívoca 
ou diretamente com os componentes do objeto - o discurso. Contudo, podemos notar uma relação que pode se considerar mais ou menos imediata entre a linguística e a língua, a psicanálise e o sujeito e o materialismo histórico e a história. É conveniente frisar que os elementos, quer sejam do discurso, ou da forma como se aborda esse discurso no momento de sua análise, não podem ser encarados por uma visão que caminhe para a inércia ou que tente mantê-los isolados entre si, uma vez que se constroem de maneira fluida e multiforme. Brito (2012, p. 543) nos lembra que essa constituição nos coloca diante de "um projeto que reside na investigação da materialidade e da historicidade dos enunciados, ou seja, um projeto que não sacrifica nem o aspecto linguístico do discurso, nem seu aspecto histórico". Com o objeto inicialmente definido, pergunta-se qual seria a motivação para construir um material com características tão complexas e "instáveis". Para além da leitura superficial, que cola o código a um sentido concebido como pré-estabelecido, e para além de uma leitura interpretativa, baseada no subjetivismo e no individualismo, utiliza-se das conexões entre língua/ linguística, indivíduo/sujeito e história/materialismo histórico para propor uma leitura que procura compreender a língua fazendo sentido, enquanto trabalho simbólico, parte do trabalho social geral, constitutivo do homem e da sua história" (ORLANDI, 2015, p. 13). Dito de outra forma, "a atividade de leitura deve centrar-se não apenas no que está dito, mas também no que está implícito" (BRITO, 2012, p. 544).

Pêcheux (1983, p. 53) ressalta que a pesquisa linguística, procurando analisar o discurso

começaria assim a se descolar da obsessão da ambiguidade (entendida como lógica do "ou... ou") para abordar o próprio da língua através do papel do equívoco, da elipse, da falta, etc.... Esse jogo de diferenças, alterações, contradições não pode ser concebido como amolecimento de um núcleo duro lógico: a equivocidade, a "heterogeneidade constitutiva.

Para complementar nossa explicitação sobre o objeto da AD, consideramos a observação de Orlandi (1990, p. 8) a respeito da Análise do Discurso bastante pertinente, pois evidencia o fato essencial de que a AD é um campo em que teoria, objeto e análise são erigidos de forma interligada, não sendo possível considerar um dos elementos sem a presença dos demais:

quer se a considere como um dispositivo de análise ou como a instauração de novos gestos de leitura - se apresenta com efeito como uma forma de conhecimento 
que se faz no entremeio e que leva em conta o confronto, a contradição entre sua teoria e sua prática de análise. $\mathrm{E}$ isto compreendendo-se o entremeio seja no campo das disciplinas, no da desconstrução, ou mais precisamente no contato do histórico, que constitui a materialidade específica do discurso (ORLANDI, 1990, p. 8).

O discurso é, portanto, estrutura e acontecimento quando se reconhece a dinâmica das "relações entre o que é dito aqui (em tal lugar), e dito assim e não de outro modo, a fim de se colocar em posição de "entender" a presença de não-ditos no interior do que é dito" (PÊCHEUX, 1938-1983, p. 44). A estrutura oportuniza a estabilização do enunciado, conferindo-lhe a materialidade, enquanto o acontecimento, nos poros do enunciado, assenta as relações entre sujeito, história, memória e esquecimento.

\section{A NOÇÃO DE MEMÓRIA DISCURSIVA}

A teoria do discurso foi construída em uma trajetória conhecida e dividida, didaticamente, como Três épocas. A fase demarcada como "primeira época" faz uma exploração metodológica da noção de maquinaria discursiva estrutural, propondo um sujeito atravessado pela ideologia e pelo inconsciente. Nesse período, Pêcheux desenvolve as noções de condições de produção e formações imaginárias, concluindo que "a existência do outro está subordinada ao primado do mesmo" (1997; 2001 b), ou seja, por um lado as condições de produção correspondem às relações de forças internas entre os protagonistas do discurso e por outro, as condições ampliadas de produção permitem observar como o discurso sempre se remete a um outro, direta ou indiretamente. Já a "segunda época" é marcada por tentativas de elaborar uma proposta teóricometodológica para a análise do discurso. Em 1969, com a publicação do livro Por uma análise Automática do Discurso, Pêcheux deixa claro sua tentativa de instaurar uma metodologia para a análise de conteúdo. A "terceira época" evidencia a emergência de novos procedimentos da $A D$, através da desconstrução das maquinarias discursivas. Segundo Brito (2012, p. 555), tal fase manifesta uma reorientação do projeto teórico e político da AD.

Entendemos que em cada fase existe o germe da noção de memória discursiva, por isso julgamos interessante discorrer, mesmo que de forma breve, a respeito das três épocas pois, embora o conceito de memória discursiva tenha sido cunhado por Michel Pêcheux somente em 1983, entendemos que seria um equívoco considerar que a construção dessa 
noção tenha acontecido de forma abrupta ou pontual. Na $1^{\text {a }}$ fase, a análise discursiva consistia principalmente em detectar e construir sítios de identidades parafrásticas intersequenciais, ou seja, entre fragmentos de sequências saídas de discursos empíricos diferentes enquanto pontos de variação combinatória. Esse trabalho era desenvolvido com base na ideia de uma álgebra discursiva que permitiria construir formalmente a estrutura geradora do processo associado ao corpus (PÊCHEUX, 1983 apud GADET; HAK, 1987 p.312). Podemos dizer que um possível pensamento inicial relacionado à noção de memória discursiva estaria nas paráfrases, já que estas são retomadas de sentidos mais ou menos estabilizados, por meio de sintagmas diferentes. Maldidier (1993, p. 107-119) pontua também que, no final dos anos 1960, a Análise do Discurso propôs aos linguistas um modo de abordagem da relação entre a língua e a história (ambas perpassadas por/pelas memórias discursivas).

$\mathrm{Na} 2^{\text {a }}$ fase, a análise discursiva "ganha" a noção de interdiscurso, a qual é utilizada para designar o exterior específico de uma formação discursiva, no ato em que o interdiscurso surge nesta formação discursiva para constituí-la em lugar de evidência discursiva, sendo que a maquinaria discursiva é concebida como o resultado paradoxal da invasão de um "além" exterior e interior (PÊCHEUX, 1983 apud GADET; HAK, 1987 p.314). O interdiscurso poderia ser visto, então, como um estabelecimento de jogo de forças entre os vários fatores que compõem os discursos, sendo que dentre estes fatores, a memória discursiva também pode ajudar a compor tanto as junções quanto as disjunções de uma determinada formação discursiva. Já a $3^{\text {a }}$ fase, marcada por inúmeros questionamentos e (re)construções, reconhece o discurso de um outro, que é colocado em ação pelo sujeito, ou o discurso do sujeito é colocado em cena como um outro, a heterogeneidade (PÊCHEUX, 1983 apud GADET; HAK, 1987 p.315-317). Ao reconhecer que um sujeito é atravessado pelo outro, momento em que o que acredita ser seu próprio discurso lhe escapa, podemos reconhecer a força das memórias discursivas outras, às quais somos perpassados e por elas também constituídos.

A memória discursiva, então, diz respeito aos elementos que colaboram com os sentidos, de modo que esses elementos são inscritos coletiva e historicamente, possibilitando que sejam atribuídos efeitos de sentido às materialidades linguísticas. França (2016, p. 4) aponta que, sendo um espaço de retomadas de discursos anteriores, a memória é um "componente balizador de um embate entre forças ideológicas que 
objetivam reestabelecer os implícitos e forças antagônicas que lutam para desestabilizar e desregular os já-ditos". Pêcheux (2010, p. 52) define a noção de memória discursiva como "aquilo que, face a um texto que surge como acontecimento a ler, vem restabelecer os 'implícitos' (quer dizer, mais tecnicamente, os pré-construídos, elementos citados e relatados, discursos-transversos, etc.) de que sua leitura necessita: a condição do legível em relação ao próprio legível". Esse funcionamento da memória envolve um jogo de forças, na medida em que o já-dito vai sendo reatualizado, com vistas à manutenção de uma regularização já existente por meio de estabilização parafrástica; por outro lado, esse jogo pode gerar uma "desregulação" que acaba por perturbar a rede dos implícitos (PÊCHEUX, 2010, p. 53). Ainda no que refere à definição da noção de memória discursiva, Pêcheux destaca que

uma memória não poderia ser concebida como uma esfera plena, cujas bordas seriam transcendentais históricos e cujo conteúdo seria um sentido homogêneo, acumulado ao modo de um reservatório: é necessariamente um espaço móvel de divisões, de disjunções, de deslocamentos e de retomadas, de conflitos de regularização... Um espaço de desdobramentos, réplicas, polêmicas e contradiscursos (PÊCHEUX, 2010, p. 56)

É por meio dessa imbricação que a memória discursiva é (re) estabelecida, permitindo a leitura e a atribuição de efeitos de sentidos aos discursos, o que procuramos compreender na análise das materialidades discursivas no tópico que segue.

\section{A ANÁLISE: SENTIDOS SOBRE EDUCAÇÃO, TRABALHO E DESENVOLVIMENTO SOCIAL}

Uma das materialidades recortadas para a presente abordagem, como já sinalizamos, versa sobre as estratégias adotadas pelo governo brasileiro para atingir a economia digital. Essa materialidade integra o e-book que faz parte de uma rede de ações coordenadas pelo Ministério da Ciência, Tecnologia, Inovação e Comunicação (MCTIC). Vejamos, a seguir, a primeira materialidade recortada da seção "Educação e Capacitação Profissional": 


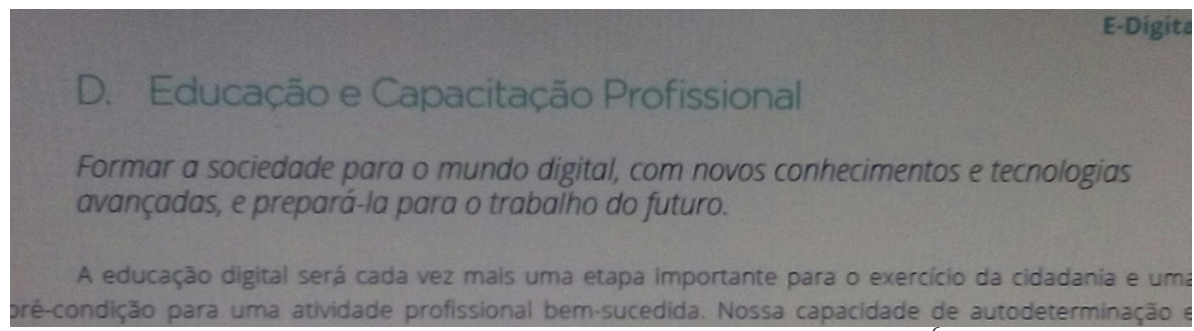

Figura 1: E-book "Estratégia brasileira para a transformação digital ${ }^{6}$

A construção trabalho do futuro propicia a retomada de um dizer considerado popular no Brasil, sentença cunhada pela primeira vez como título do livro escrito por Stefan Zweig, publicado em 1941: Brasil, país do futuro. O autor, que se refugiou no Brasil na época da Segunda Guerra, na citada obra, descreve os "hábitos da cultura brasileira que se destacam aos olhos estrangeiros, como o simples fato de sempre haver um café fresco para receber um visitante". ${ }^{7}$ O título do livro de Stefan se mantém, ora por sinônimos e paráfrases, ora pela emersão de palavras que, ainda que sejam lexicalmente diferentes dos sintagmas iniciais, fazem emergir efeitos de sentido que se aproximam: sintagmas como "mundo digital", "tecnologias avançadas", do mesmo modo podem remeter às relações do "trabalho do futuro". A relação entre as formulações Brasil, país do futuro e Trabalho do futuro emerge na medida em que a premissa que parece se estabelecer é a de que, para um país que se prepara para o futuro, há a necessidade, também, de instruir sua população para empregos do futuro.

Nesse contexto, o que nos parece ser considerado emprego do futuro é aquele que abarca os diversos usos da tecnologia digital, seja nas indústrias, no manejo de máquinas sofisticadas, utilizadas na linha de montagem de incontáveis produtos, na área administrativa, com o uso de computadores e softwares, na área científica, com maquinários de análise, entre outros. Diante disso, os efeitos de sentidos que emergem são de que temos um país promissor, que possui potencialidades prontas a serem exploradas, mas que ainda não pode ser considerado o país do futuro, visto que não tem trabalhadores adequados aos trabalhos que o futuro requer. É, então, por meio da educação e capacitação profissional, do estabelecimento da cultura digital no país que haverá desenvolvimento social, o que nos parece estar fortemente atrelado à digitalização das relações e à inserção do país no mundo digital. Isso se dá em razão 6 Disponível em: <www.mctic.gov.br/estrategiadigital>. Acesso em: 10 abr. 2019.

$7 \quad$ Disponível em: <https://www.lpm.com.br/site/default.asp?Template=../livros/layout_produto. asp\&CategorialD=6170 51\&ID=548061>. Acesso em: 10 abr. 2019. 
do que emerge no recorte em questão: uma nação que apresenta tais características é considerada um país de "primeiro mundo", ou seja, um país do futuro. Essa formulação "país do futuro" também foi utilizada em slogans políticos, como o que vemos na materialidade que segue:
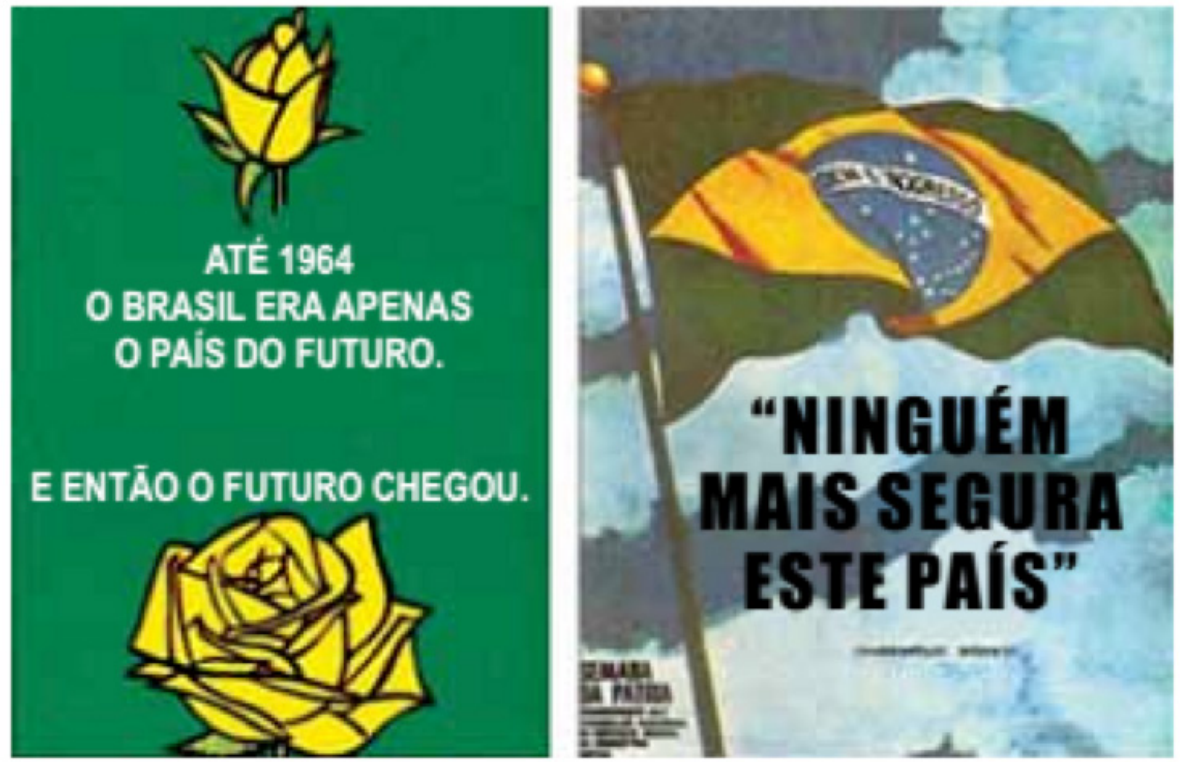

(Flavio de Campos e Regina Claro. Oficina de história, vol. 3, 2013.)

Figura $2^{8}$

O enunciado Até 1964 o Brasil era apenas o país do futuro nos possibilita a retomada do título do livro de Zweig (Brasil, país do futuro) e faz vir à tona os sentidos de um país promissor e receptivo, pronto para receber o futuro. O sintagma futuro pressupõe bons acontecimentos, boas oportunidades, sensação de esperança naquilo que está por vir. A imagem de uma rosa pode indiciar crescimento, mudança e, ainda, o desabrochar tal qual uma planta sofre durante seu desenvolvimento; a cor amarela - não comum para rosa - também sinaliza otimismo e prosperidade. Em E então o futuro chegou, temos o efeito de sentido de que o brasileiro não precisaria mais esperar, pois o futuro já é aquele momento, tempo marcado pela forma do pretérito perfeito (chegou) que indica uma ação concluída. Do lado direito da Figura 2, a imagem evoca um patriotismo ao colocar a bandeira brasileira ao fundo, juntamente 8 Disponível em : <https://www.qconcursos.com/questoes-de-vestibular/questoes/ceac06cd-29>. Acesso: 23 abr. 2019. 
com a formulação Ninguém mais segura este país, que preconiza o entendimento de que alguém um dia já segurou, barrou, atrasou o país, possibilitando o sentido de que a política militar, ao contrário dos governos anteriores, conseguiria propiciar todo o potencial que o Brasil poderia desenvolver, ao mesmo tempo que se coloca como um possível "libertador", pois só é preciso ser solto, não ser segurado, quem está ou esteve preso. Ainda o efeito de sentido possível é o da certeza de que o Brasil "daria certo", pois o futuro havia chegado; o país não estava mais esperando a promessa vindoura de dias melhores e avanços no que diz respeito à educação, trabalho, desenvolvimento social, e outras áreas. O futuro está no presente, no Brasil que ser quer, em transição e em ascensão, como vemos também na Figura 3:

\section{MINISTÉRIO DOS TRANSPORTES}

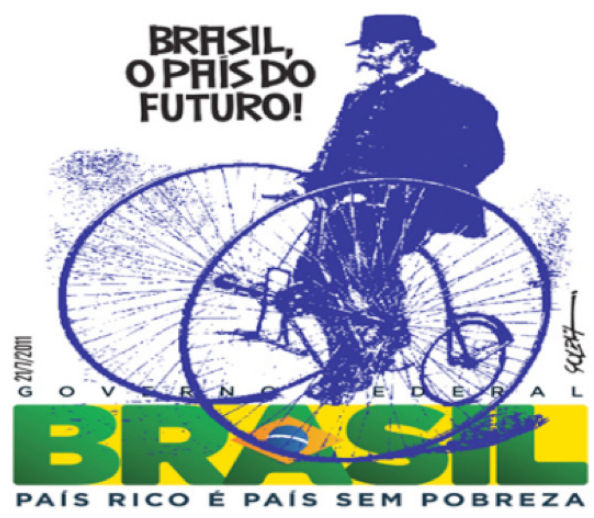

Figura $3^{9}$

A Figura 3 restabelece elementos já citados - Brasil, país do futuro - e apresenta outro enunciado: Brasil, país rico é país sem pobreza ${ }^{10}$, ou seja, país do futuro = país rico, sem pobreza. A imagem de um homem sentado em um velocípede antigo, modelo Penny Farthing, criada no final dos anos $1860^{11}$, causa um certo estranhamento na medida em que parece apontar para direções diferentes das que permeiam os enunciados. A presença do velocípede sedimenta o sentido de que o Brasil só será 9 Disponível em: <http://molinacuritiba.blogspot.com/2011/07/charge-do-solda-brasil-o-pais-dofuturo.html>. Acesso em: 10 abr. 2019.

10 Campanha utilizada durante o governo Lula/Dilma. Para melhor visualização desse período do governo de Dilma, recomendamos a leitura do artigo A gestão macroeconômica do governo Dilma (2011/2012). Disponível em: <http://www.scielo.br/scielo.php?script=sci_arttext\&pid=S0101-33002013000300011>. Acesso em: 10 abr. 2019.

11 Disponível em: < https://autos.culturamix.com/bicicleta/bicicletas-antigas>. Acesso em: 09 fev. 2019. 
o país do futuro se não houver pobreza; daí, sua riqueza, efeitos de sentido que rumam à uma crítica de que o Brasil precisa realmente progredir, pois ainda funciona de forma atrasada se comparada aos aparatos (tecnológicos) atuais. A pobreza, nessa Figura, é ressignificada e desloca os pré-construídos instaurados pela memória discursiva ao longo do tempo: a carência envolve não só a falta de acesso ao que é essencial (econômica), mas especialmente a ausência de recursos de outras naturezas (cultural, educacional, social etc). Por outro lado, emerge, ainda, da Figura em questão o sentido de que país rico não se faz somente com dinheiro, mas também de oportunidades.

A formulação Brasil, país do futuro é retomada e deslocada (do campo de possibilidade para o de realidade) em uma outra materialidade discursiva, fazendo emergir outros efeitos de sentido, conforme vemos a seguir na Figura 4:
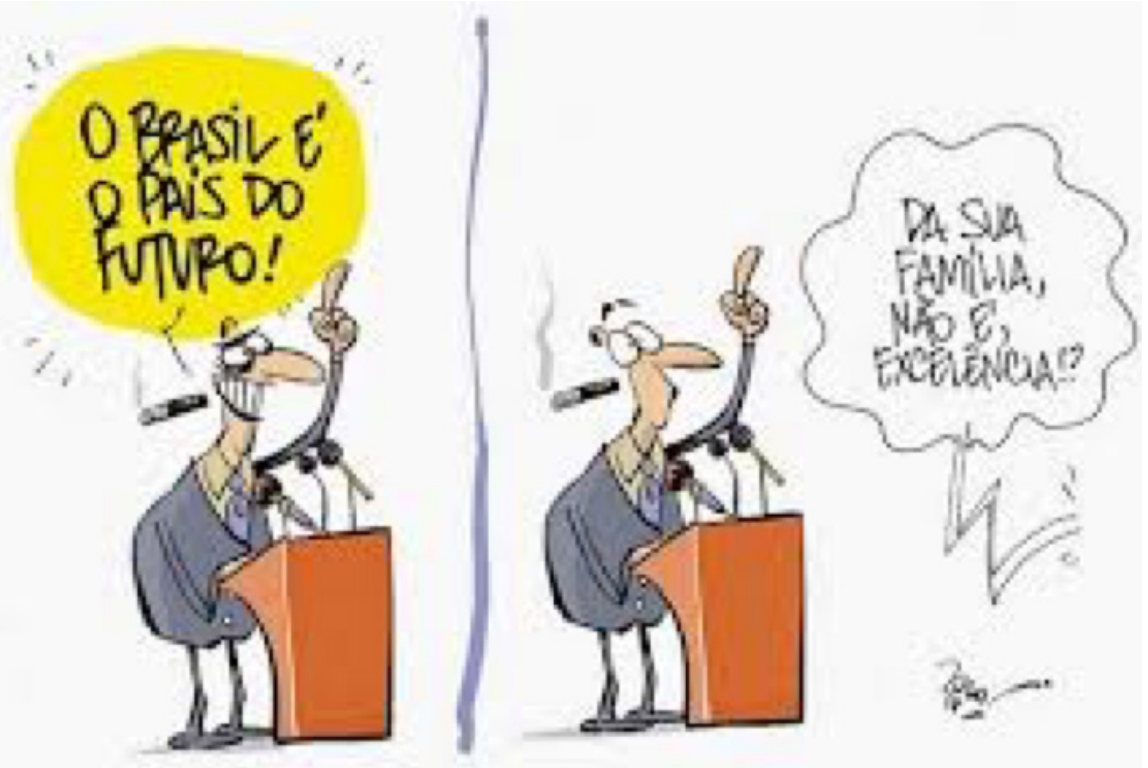

Figura $4^{12}$

Do lado esquerdo da Figura 4, há um político que reproduz em tom afirmativo, em um palanque, o mesmo enunciado do livro de Stefan Zweig, cuja pretensão parece ser a de gerar uma sensação de 
nacionalismo e esperança no público (subentende-se que há um público que ali, mesmo que este não esteja retratado na imagem), além de apontar que o Brasil é aquele das promessas e das potencialidades ainda não exploradas. Notamos que a expressão facial do político anuncia alguém que está contente, porém com uma fisionomia que aparenta ser malévola, manifestando a memória de político como alguém que é desonesto, ladrão, espertalhão e, muitas vezes, mentiroso. Do lado direito, vemos um enunciado que remete a alguém do público que assiste ao pronunciamento e rebate: da sua família, não é, excelência. Temos aí uma referência forte ao imaginário do político desleal, que rouba o dinheiro do povo, pois quando juntamos as formulações, temos: O Brasil é o país do futuro... da família do político, o que vem ratificar a ideia de desonestidade. Esses efeitos de sentido se completam com a expressão de olhar conclusivo do outro sujeito que enuncia, com o olhar arregalado que evidencia um tom assustado e, ao mesmo tempo, certeiro com relação a esse perfil de político desonesto, para quem o único futuro garantido (pelo menos aquele que figura no nível econômico) é o dele mesmo e de seus familiares, em detrimento da população em geral.

Na Figura 5, temos uma imagem que também retoma o dizer Brasil, país do futuro e apresenta uma ruptura ao colocar em circulação as formulações PAÍS DO FUTURO e IDADE MÉDIA em forma de destaque. Tem-se uma reflexão que envolve o aspecto temporal, já que quando se pensa em futuro emerge o sentido de ir em frente, de surgimento de ideias novas e superação de conceitos antigos. Porém, a construção Idade Média parece apontar para uma época passada, conhecida como Idade das Trevas, período em que a Igreja teve a forte influência sobre as deliberações do governo e que as decisões eram tomadas com base essencialmente na doutrina católica e nos dogmas da Igreja. Desse modo, o conjunto da materialidade coloca em questionamento o fato de o país (do futuro) estar voltando à idade média, já que tem discutido temas considerados polêmicos e conservadores que nada sinalizam em termos de progresso para um país. A cor vermelha do fundo da Figura é, em geral, atribuída a grupos progressistas que prezam a revolução e a inovação, efeito que é potencializado pela circulação da materialidade na revista Cult ${ }^{13}$, também conhecida pelo seu tom de protesto.

13 A CULT é uma revista mensal voltada às áreas da arte, cultura, filosofia, literatura e ciências humanas. Com uma circulação de 35 mil exemplares, distribuídos em âmbito nacional, a publicação é conhecida por sua independência editorial - o que sempre a levou a tratar, em seus vinte anos de existência, de temas pouco explorados normalmente pelos mais variados veículos do jornalismo cultural. Disponível em: <https://revistacult. uol.com.br/home/sobre/>. Acesso em: 01 abr. 2019. 


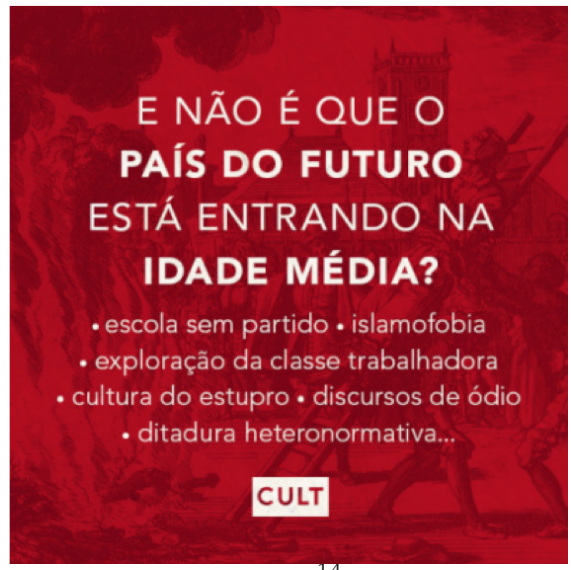

Figura $5^{14}$

Os temas listados na Figura 5 são considerados de grande repercussão quando se trata de políticas públicas. A proposta de aprovação de um projeto intitulado escola sem partido, por exemplo, sinaliza que estamos diante de um governo que prejudica uma parcela da população ao silenciar sua voz, com o argumento da possibilidade de neutralidade diante dos fatos cotidianos e históricos. Também os outros temas - a islamofobia, a cultura do estupro, os discursos de ódio, a ditadura heteronormativa, parte do projeto do atual governo, remontam a preconceitos que são condenados e que têm sido desconstruídos por diversos estudos e leis, de modo que evidenciam o retrocesso que os discursos da figura apresentam. A exploração da classe trabalhadora traz à tona a reforma trabalhista efetivada, a qual preconizou o que se nomeia flexibilização das leis trabalhistas, mas que, para muitos, significa a perda de direitos e o recuo frente à luta dos trabalhadores que são a maior parte da população brasileira.

A Figura 6 ressignifica o enunciado Brasil, o país do futuro: de elogio ao povo e as terras brasileiras, passou a ser utilizado em tom sarcástico e de crítica em relação às diretrizes políticas do país. A formulação Brazil Still the Country of the future (em uma tradução livre: o Brasil ainda continua sendo o país do futuro) faz emergir o sentido de que o futuro tão alardeado nunca chega, e o que o país sempre ficará como uma promessa que nunca se concretizará. Outro aspecto que chama a atenção é a ilustração de um índio, com várias cores em sua face, remetendo a questão da miscigenação brasileira e fazendo referência ao primeiro habitante do Brasil, haja vista que as cores estão na face do 14 Disponível em:<https://luizmuller.com/2016/08/01/o-pais-do-futuro/>. Acesso em: 10 abr. 2019. 
índio, o primórdio brasileiro. A pequena bandeira pendurada em seu colar pode trazer o efeito de sentido de um país que não lhe cabe, um país que não consegue abarcar a grandeza e a diversidade de um povo. O olhar do índio nos parece longe e abnegado, o de alguém que espera, talvez, algo que nunca irá chegar.

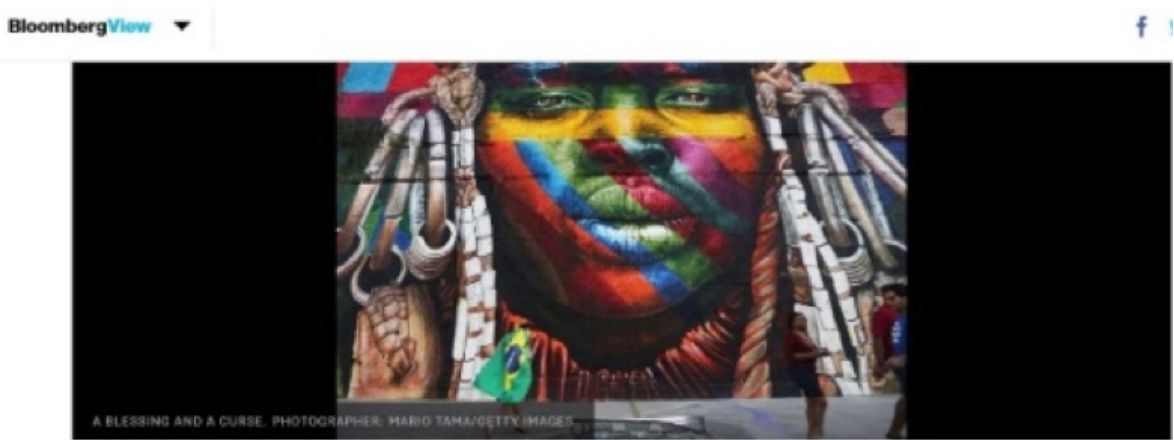

\section{Brazil Is Still the Country f of the Future}

Figura $6^{15}$

A foto ${ }^{16}$ intitulada "A blessing and a curse" ("Uma benção e uma maldição", em tradução livre) sinaliza o olhar que o estrangeiro tem sobre o ser brasileiro, ou seja, parece que o Brasil é visto pelas suas potencialidades que não são exploradas por conta das negligências dos governantes do país. Assim, ser brasileiro nos confere uma benção e uma maldição, já que vivemos em um país que, em tese, tem toda a probabilidade de se desenvolver, mas que não o faz a contento por causa de seus gestores. Diante disso, é possível perceber a emergência de ressonâncias interdiscursivas (paráfrases) que ora mantêm o sentido do dizer inicial (Brasil, país do futuro), ora provocam uma disjunção de efeitos de sentido (Formar a sociedade para o mundo digital, com novos conhecimentos e tecnologias avançadas e prepará-la para o trabalho do futuro; Até 1964 o Brasil era apenas o país do futuro. E então o futuro chegou; O Brasil é o país do futuro!... Da sua família, não é excelência?; E não é que o país do futuro está entrando na Idade Média?; O Brasil ainda continua sendo o país do futuro.)

Temos, nesses deslocamentos, a repetição da expressão futuro, a 15 Disponível em: <https://www.bloomberg.com/opinion/articles/2016-08-11/brazil-is-still-the-countryof-the-future > Acesso em: 10 abr. 2019.

16 Do fotógrafo Mario Tama. 
qual remete à esperança de que o país pode melhorar e se desenvolver social e economicamente, fazendo emergir o discurso que parece ser fundante do brasileiro, que não se reconhece como povo de um país que está em desenvolvimento, mas de um lugar que sempre esteve em declínio e que isso será superado um dia. Contudo, a utilização de futuro nem sempre faz emergir o sentido de possibilidade e de progresso, como, por exemplo, quando tal expressão vem acompanhada de modalizadores de estado ("país do futuro x entrando na Idade Média" e "continua sendo o país do futuro"), o que expressa o desagrado com a situação e aponta para uma crítica à condução das decisões políticas do país. Outras formulações que também fazem vir à tona a desaprovação quanto ao modus operandi dos governantes são: O Brasil é o país do futuro!... Da sua família, não é excelência? e O Brasil continua sendo o país do futuro.

\section{CONSIDERAÇÕES FINAIS}

A partir da análise das materialidades, é possível vislumbrar vários dos pontos que Pêcheux (2010) elencou a respeito da memória discursiva, os quais vêm a ser o jogo de ressignificação e deslocamentos que ocorrem na língua e que se dão na emergência da memória na forma de (novas) paráfrases; mesmo que sob a forma de contradiscursos, as alusões que uma manifestação discursiva pode fazer a discursos anteriores os interligam historicamente. É possível notar, também, que o enunciado trabalho do futuro pode fazer emergir as memórias discursivas relacionadas ao enunciado Brasil, país do futuro. A análise faz aflorar a ideia de que o Brasil sempre está no futuro, um futuro que nunca chegou e parece que nunca chegará, uma vez que suas potencialidades são negligenciadas dia-após-dia, governo após governo, de maneira que o efeito nada promissor da expressão futuro compromete várias instâncias, dentre elas a das políticas públicas voltadas ao desenvolvimento social.

Outro ponto que destacamos é a noção de educação que decorre da sentença analisada, na qual a educação é considerada como salvadora da pátria ao apontar que é através da qualificação profissional que o país avançará socialmente. Ao mesmo tempo em que o discurso político nos faz apreender esse efeito de sentido, vemos nas figuras analisadas que as práticas da classe política não têm sido concomitantes aos discursos produzidos, fazendo emergir a sensação de paradoxo, podendo derivar daí novos sentidos, muitas vezes sarcásticos, da expressão futuro. Dito de outro modo, as ressonâncias interdiscursivas (paráfrases) que podem emergir são diversas, conforme já sinalizamos. Um enunciado que 
inicialmente foi cunhado na tentativa de elogiar uma nação pode ser recuperado em um movimento diferente que produzirá outro(s) efeito(s) de sentido(s). Com isso, é possível perceber a flutuação de sentidos do dizer considerado inicial, segundo as condições de produção e o contexto histórico de circulação das formulações.

Nessa perspectiva, podemos afirmar que a memória discursiva está sempre em movimento, ora se ressignificando, ora se deslocando, em alguns momentos se apagando e em outros ressurgindo com/nos discursos, já que é constituída por faltas, lacunas repletas de historicidade (MARIANI, apud ORLANDI, 2001. p. 41).

\section{REFERÊNCIAS}

ACHARD, P., et. al. Papel da memória. Tradução de José Horta Nunes. Campinas: Pontes, 2010.

BRITO, L. A. N. de. (Re)Lendo Michel Pêcheux: como a análise do discurso de linha francesa apreende a materialidade discursiva?. Eutomia (Recife), v. jul/2012, p. 542- 562, 2012.

GADET, F.; HAK, T (Org.). Por uma análise automática do discurso: uma introdução à obra de Michel Pêcheux. Tradução de Bethania S. Mariani, [et. al]. 3 ed. Campinas: Editora Unicamp, 1997.

GARCIA, T. M. A análise do discurso francesa: uma introdução nada irônica. Working papers em Linguística, UFSC, n.7, 2003.

GREGOLIN, M. do R. Foucault e Pêcheux na construção da análise do discurso - diálogos e duelos. São Carlos: Claraluz, 2004.

FRANÇA, T. M. Um olhar sobre o conceito de memória discursiva de Michel Pêcheux. Interletras, n. 1807-1597, v. 4, 2016.

MAINGUENAU, D. Termos-chave da análise do discurso. Tradução de Márcio Venício Barbosa, Maria Emília Amarante Torres Lima. Belo Horizonte: Ed. UFMG, 1998.

MALDIDIER, D. A inquietação do discurso: (re)ler Michel Pêcheux hoje. Tradução de Eni Orlandi, Campinas: Pontes, 2003.

ORLANDI, E. P. (Org.) Discurso fundador: a formação do país e a construção da identidade nacional. São Paulo: Pontes, 2001.

ORLANDI, E. P. Análise de discurso: princípios e procedimentos. Campinas: Pontes Editores, 2015.

PIOVEZANI, C.; SARGENTINI, V. (Org.). Legados de Michel Pêcheux: inéditos em análise do discurso. São Paulo: Contexto, 2018.

PÊCHEUX, M. O Discurso - estrutura ou acontecimento. Tradução de Eni Orlandi. Campinas: Pontes Editores, 1990.

PÊCHEUX, M. O papel da memória. In: ACHARD, P. et al. O papel da memória. Trad. 
José Horta Nunes. 3 ed. Campinas: Pontes, 2010.

PÊCHEUX, M. Rôle de la mémoire. In: Histoire et linguistique. Paris, Éditions de La Maison des Sciences de l'Homme, 1983.

SANTOS, H. S. Repensando a noção de interpretação: transparência ou opacidade? Revista Alpha, v. 13, p. 23-37, 2012.

ZWEIG, S. Brasil, país do futuro. Rio de Janeiro: Guanabara, 1941.

Recebido em: 06/06/2019

Aceite em: 16/06/2019 